\title{
Further Support of Conspecificity of Oak and Mango Powdery Mildew and First Report of Erysiphe quercicola and Erysiphe alphitoides on Mango in Mainland Europe
}

\begin{abstract}
Marie-Laure Desprez-Loustau and Marie Massot, UMR 1202 BIOGECO, INRA, Univ Bordeaux, 33610 Cestas, France; Nicolas Feau, Department of Forest and Conservation Sciences, British Columbia, The University of British Columbia, Vancouver, V6T 1Z4, Canada; Tania Fort, UMR 1202 BIOGECO, INRA, Univ Bordeaux, 33610 Cestas, France; Antonio de Vicente, Instituto de Horticultura Subtropical y Mediterránea La Mayora (IHSM-UMA-CSIC), Departamento de Microbiología, Facultad de Ciencias, 29071, Málaga, Spain; Juan Antonio Torés, Instituto de Horticultura Subtropical y Mediterránea La Mayora (IHSM-UMA-CSIC), Algarrobo-Costa, 29750, Málaga, Spain; and Dolores Fernández Ortuño, Instituto de Horticultura Subtropical y Mediterránea La Mayora (IHSM-UMA-CSIC), Departamento de Microbiología, Facultad de Ciencias, 29071, Málaga, Spain; and Instituto de Horticultura Subtropical y Mediterránea La Mayora (IHSM-UMA-CSIC), Algarrobo-Costa, 29750, Málaga, Spain
\end{abstract}

\begin{abstract}
Mango leaves and inflorescences infected by powdery mildew in southern Spain were analyzed using multigene sequencing (ITS +4 singlecopy coding genes) to identify the causal agent. Erysiphe quercicola was detected in $97 \%$ out of 140 samples, collected in six different orchards in the Malaga region. Among these, a small proportion also yielded E. alphitoides (8\% of all samples) and E. alphitoides was found alone in $3 \%$ of samples. A phylogenetic approach was completed by cross inoculations between oak and mango, which led to typical symptoms, supporting the conspecificity of oak and mango powdery mildews. To our knowledge, this is the first report of E. quercicola and E. alphitoides

causing powdery mildew on mango trees in mainland Spain, and thus mainland Europe, based on unequivocal phylogenetic and biological evidence. Our study thus confirmed the broad host range of both E. quercicola and E. alphitoides. These results have practical implications in terms of the demonstrated ability for host range expansion in powdery mildews. They also open interesting prospects to the elucidation of molecular mechanisms underlying the ability to infect single versus multiple and unrelated host plants since these two closely related powdery mildew species belong to a small clade with both generalist and specialist powdery mildews.
\end{abstract}

For a long time, powdery mildew fungi have been considered as highly specific pathogens, i.e., a given species can infect only a narrow range of host plants, usually in the same genus. This view was probably strongly influenced by the fact that many powdery mildews of crop plants, such as Blumeria graminis in cultivated cereals, show strict host specificity, with different formae speciales adapted to different host plant genera (Troch et al. 2014). Until quite recently, host range had even been used as an element in powdery mildew taxonomy, in addition to morphological criteria (Cook et al. 1997). The availability of molecular markers has dramatically improved and changed our vision on these fungi, especially in that host specificity is not as simple and narrow as previously believed. Many plant species have been shown to be infected not only by one powdery mildew species in one genus but by several related species, which makes host plant species an unreliable criterion for identification (Bereczky et al. 2015; Kiss et al. 2008). Moreover, some powdery mildew species, such as Golovinomyces cichoracearum or Phyllactinia guttata, previously thought to have a broad host range, were divided into several narrowly defined species, each confined to a single host genus (Braun and Cook 2012; Takamatsu et al. 2008). On the other hand, both molecular analyses (principally with ITS sequence) and crossinoculations studies have identified true polyphagous powdery mildew species, such as G. orontii, Leveillula taurica, or Podosphaera xanthii, which exhibit wide host range beyond the plant family level (Kirschner and Liu 2014; Lipka et al. 2008; Meeboon and Takamatsu 2015; Vági et al. 2007). Now, it is clear that within the order Erysiphales (powdery mildew fungi), and even within some genera in this order,

Corresponding author: M.-L. Desprez-Loustau;

E-mail: marie-laure.desprez-loustau@inra.fr

Accepted for publication 3 March 2017.

() 2017 The American Phytopathological Society species with broad and narrow host ranges co-occur (Schulze-Lefert and Panstruga 2011).

Among species showing wide host ranges, an interesting case is provided by the two closely related species Erysiphe alphitoides and E. quercicola, both associated with oak powdery mildew (Takamatsu et al. 2007). E. alphitoides was described in the early 20th century in France as the species responsible for the emerging disease that expanded very rapidly and caused high mortality in European oaks at that time (Mougou et al. 2008). E. quercicola was described much more recently, from observations on Quercus phillyraeoides in Japan (Limkaisang et al. 2006; Takamatsu et al. 2007), but has also been found on oaks in Europe (Mougou et al. 2008; Mougou-Hamdane et al. 2010). Molecular phylogenies based on nuclear ribosomal DNA strongly suggested that these two species may originate from Asia and have a common ancestor infecting species of the Quercus genus (oaks), within the Fagaceae family (Takamatsu et al. 2007, 2015). However, both E. alphitoides and E. quercicola seem to have a very broad host range. Indeed, samples collected from a wide range of host plant species (principally tropical trees) in families distant from Fagaceae, such as Acacia spp., Citrus spp., Hevea brasiliensis, Mangifera indica, or Anacardium occidentale, although described under a variety of names, were shown to have the same morphology and ITS sequence as E. quercicola (Limkaisang et al. 2006). Similarly, isolates from Paeonia lutea, Wisteria sinensis, and $M$. indica were suggested to be very closely related or conspecific to E. alphitoides (Henricot and Cook 2007; Limkaisang et al. 2006; Takamatsu et al. 2015). The list of reported host species for the two Erysiphe spp. has grown even longer in recent years (Beenken 2017; Bereczky et al. 2015; Denton et al. 2016; Kirschner and Liu 2014). It is interesting to note that mango ( $M$. indica) appears as a shared host species among the two Erysiphe species.

Mango is a tropical tree species originating from India. Early Portuguese explorers gave the fruit and tree its name (derived from the local Tamil name), and were the first to establish a mango trade in the 16th century, bringing mangos to South America. Mango is now grown for commercial production in many tropical and subtropical regions in the 
world, and in a few areas in Europe with Mediterranean climate. In Spain, mango was first introduced in the late 18th century in the Canary Islands but its commercial cultivation only started at the beginning of the 1970s in these islands and during early 1980s in southern mainland Spain. The current cultivated area in Spain is greater than 4,700 ha (Anonymous 2015). Powdery mildew has been reported as a destructive disease of mango in most growing areas worldwide, with yield loss estimates of 15 to $20 \%$ (Nasir et al. 2014). The fungus attacks all young tissues: tender leaves, inflorescences, and fruits in early stages. Severe infection induces flowers and small fruits to abort and fall off. The disease was first described in Brazil in 1914 (Briton-Jones 1925); however, it was known to be present in India before 1874 (Nelson 2008). So far in Europe, the only reports of powdery mildew on mango trees include Crete in Greece and the Canary Islands in Spain (CABI/EPPO 2010; Nasir et al. 2014). Like other powdery mildew diseases, the symptoms are characterized by the whitish, talcum-like, powdery mycelium growth on the affected parts (Nasir et al. 2014). Wherever mango is affected by powdery mildew, only the asexual morph of the fungus, of the Pseudoidium type, has been found, with a septate and ramified mycelium forming a dense coat of branching hyphae (diameter ranging between 4.1 and $8.2 \mu \mathrm{m})$ on the surface of the host. Unbranched conidiophores (64 to $163 \mu \mathrm{m}$ ) emerge from the mycelium and carry at their ends a single, hyaline, unicellular, and elliptical conidium (33 to $43 \mu \mathrm{m}$ long $\times 21$ to $28 \mu \mathrm{m}$ wide; Boesewinkel 1980; Singh 2000). The teleomorph has never been found on mango, which explains difficulties related to species identification.

The causal agent of mango powdery mildew has long been named Oidium mangiferae Berthet. It has recently been renamed as Pseudoidium anacardii (F. Noack) U. Braun \& R.T.A. Cook (Braun and Cook 2012) but, as mentioned above, phylogenetic studies suggest that $P$. anacardii is conspecific to E. quercicola (Limkaisang et al. 2006; Takamatsu et al. 2015). Following recent changes in fungal nomenclature (Gams 2016), Braun (2012) proposed that E. quercicola, although more recent than the anamorph-typified name $P$. anacardii, could be accepted, with $P$. anacardii as a synonym. Strong similarity of rDNA sequences ( $>98 \%$ ) between few isolates of $O$. mangiferae and E. alphitoides sensu stricto based on rDNA sequences added to this complexity (Limkaisang et al. 2006; Takamatsu et al. 2015).

Phylogenetic data showing close relatedness between oak and mango powdery mildew supported an old inoculation experiment performed by Boesewinkel (1980), who suggested that oak and mango powdery mildew in New Zealand were caused by the same species. The interpretation of these results had however been questioned (Nasir et al. 2014). It is noteworthy that among the various hypotheses attempting to explain the sudden outbreak of oak powdery mildew in Europe in the early 1900s, some authors had proposed that the fungus might have been inadvertently introduced in Portugal on exotic plants from former Portuguese colonies (Raymond 1927; Torrend 1909).

After the recent observation of powdery mildew damage in mango orchards in southern Spain, the goal of the present study was to clarify whether the same species as those reported for oak powdery mildew, i.e., E. alphitoides and E. quercicola were involved. More specifically, we addressed the following points: (i) identification of species causing natural mango infection in southern Spain, based on molecular data, not only from ribosomal DNA but also using four additional genes that were shown to be reliable to separate the two closely related species among other Erysiphe spp. (Feau et al. 2011); and (ii) experimental demonstration that E. alphitoides and/or E. quercicola can both infect oak and mango, using cross inoculations.

\section{Materials and Methods}

Powdery mildew sampling. Samples were collected in six mango orchards located in several districts (Algarrobo-Costa, Cajiz, Torrox, and Lagos) of the Axarquía region in southern Spain during spring 2016 (Table 1, Fig. 1). In each orchard, leaves and/or inflorescences that exhibited typical powdery mildew symptoms (Fig. 2A and B) were taken from five mango trees distant from one another by at least 25 meters. Oaks are quite rare in this area; only one tree (Quercus robur) was found infected in the vicinity of orchard A (approx. 200 meters) from which samples were collected. Five shoots, each with at least four heavily infected leaves, were taken in different parts of the tree (Fig. 2C). Upon collection, infected organs were pressed and dried until further analyses.

Molecular analyses. Discs of $5 \mathrm{~mm}$ diameter were cut off from infected leaves, and small fragments a few mm long were cut from inflorescences, hereafter referred to as "lesions." A total of 149 lesions were analyzed from mango and 19 from oak. Mango samples were designated by the field code (see Table 1), the identity of the tree within orchard (number), the organ (leaf $=\mathrm{L}$, inflorescence $=$ IN), the identity of the organ within tree (number), and, in some cases, the replicate within a same leaf or inflorescence. For example, A4L3.2 refers to a sample from Algarrobo-Costa, on tree\#4, leaf\#3, and second disc on this leaf. Oak samples were designated as MalQrx, with $x$ the identity (number) of the leaf. DNA was extracted directly from the lesions, i.e., without reinoculation and multiplication of the fungus on leaves. The material collected was freeze-dried overnight and homogenized in a steel ball mill (TissueLyser II, Retsch, Qiagen). Genomic DNA was extracted using the Invisorb Spin plant Mini kit, according to manufacturer's instructions. Total DNA was then used as a template for PCR amplifications. All samples were amplified for a $223 \mathrm{bp}$ long fragment in the ITS1 region of rDNA, with the primers ITS1-Fungi, a universal forward primer for fungi (Gardes and Bruns 1993), and o-micro-rev, a reverse primer initially designed for E. alphitoides (Heuser and Zimmer 2002) but in a region with no SNP for E. quercicola, and thus used for amplification of both species (Marçais et al. 2017) (Table 2). A subgroup of 26 samples, representative of the sampling scheme (locations, dates, cultivars) and of the diversity of ITS sequences, was also amplified for other fragments in single-copy genes. These four genes had been previously identified as useful for phylogenetic studies in the Erysiphe genus due to their high polymorphism, e.g., 44 SNP differentiating E. alphitoides and E. quercicola (Feau et al. 2011) (Table 2). For all amplifications, PCR was carried out in a $20 \mu \mathrm{l}$ reaction volume with $2 \mu \mathrm{l}$ of genomic template DNA, $0.15 \mu \mathrm{M}$ of each primer, $0.2 \mathrm{mM}$ dNTPs, $1.5 \mathrm{mM} \mathrm{MgCl}_{2}, 10 \times$ ozyme buffer, 0.75 units Taq DNA polymerase (OZYME OZYA001-1000), and sterile Milli-Q water. The PCR was performed on a Labcycler Sensoquest thermocycler

Table 1. Origin, field code, date of collection, host, cultivar, organ, and number of samples collected from different mango orchards in La Axarquia (Malaga)

\begin{tabular}{|c|c|c|c|c|c|c|}
\hline Location & Field code & Date (2016) & Host & Cultivar & Organ & Number of samples \\
\hline \multirow[t]{3}{*}{ Algarrobo-Costa } & A & 2 March & Mango & Irwin & Leaves & 25 \\
\hline & & & & & Inflorescences & 36 \\
\hline & Mal & 20 April & Oak & & Leaves & 19 \\
\hline \multirow[t]{2}{*}{ Algarrobo-Costa } & B & 11 March & Mango & Irwin & Leaves & 4 \\
\hline & & & & & Inflorescences & 12 \\
\hline Cajiz & $\mathrm{C}$ & 31 March & Mango & Kent & Inflorescences & 10 \\
\hline \multirow[t]{2}{*}{ Lagos } & D & 27 May & Mango & Keitt & Leaves & 4 \\
\hline & & & & & Inflorescences & 19 \\
\hline Lagos & $\mathrm{E}$ & 27 May & Mango & Sensation & Leaves & 20 \\
\hline \multirow[t]{2}{*}{ Torrox } & $\mathrm{F}$ & 30 March & Mango & Kent & Leaves & 9 \\
\hline & & & & & Inflorescences & 10 \\
\hline
\end{tabular}


with the following parameters: initial denaturing at $94^{\circ} \mathrm{C}$ for $3 \mathrm{~min}$, followed by 40 cycles of $94^{\circ} \mathrm{C}$, denaturing for $30 \mathrm{~s}, 55^{\circ} \mathrm{C}$ (or $56^{\circ} \mathrm{C}$ for ITS1-Fungi/o-micro-rev) annealing for $40 \mathrm{~s}$, and $72^{\circ} \mathrm{C}$ elongation for $50 \mathrm{~s}$ (or $40 \mathrm{~s}$ for ITS1-Fungi/o-micro-rev), with a final extension at $72^{\circ} \mathrm{C}$ for $7 \mathrm{~min}$. Positive and negative controls were included for each set of reactions. An electrophoresis in $2 \%$ agarose gel in TAE $1 \mathrm{X}$ (Trisacetate EDTA) buffer was run with $2 \mu \mathrm{l}$ PCR product and $4 \mu \mathrm{l}$ bromophenol blue per well for $25 \mathrm{~min}$ at $100 \mathrm{~V}$. After migration, the presence of the target DNA region (and absence in negative controls) was checked under UV following gel staining with $10 \mathrm{ppm}$ GelRed. PCR plates and the forward primer were then sent to the Genewiz Company for sequencing, using the Sanger technology. Direct sequencing, without cloning, was performed since the presence of different sequences can be detected with this method (Kovacs et al. 2011). DNA sequences were analyzed and aligned using the Bioedit software (Hall 1999). All sequences used in this study are available in GenBank (accessions KY348422-518 for powdery mildew samples initially used in the PHYLORPH study [Feau et al. 2011] and KY466597-688 for mango and oak samples obtained in this study).

Phylogenetic analyses. Sixteen mango samples that resulted in good quality sequences for ITS1 and the four nuclear-protein encoding genes (MS294, MS393, MS447, and MS550) were considered for the phylogenetic analyses. Sequences from 21 oak powdery mildew samples and from seven additional related species were added to these analyses (Feau et al. 2011; Takamatsu et al. 2007). Maximum parsimony (MP) and maximum likelihood (ML) trees were reconstructed among each gene set using PAUP ver. 4.0b10 (Swofford 2003) and PhyML (Guindon and Gascuel 2003), respectively. For ML analyses, the best-fit model of DNA substitution was chosen by performing hierarchical likelihood-ratio tests using jModeltest v. 2.1.3 on the basis of the Akaike Information Criterion (Darriba et al. 2012). Gamma distribution and proportion of invariable sites

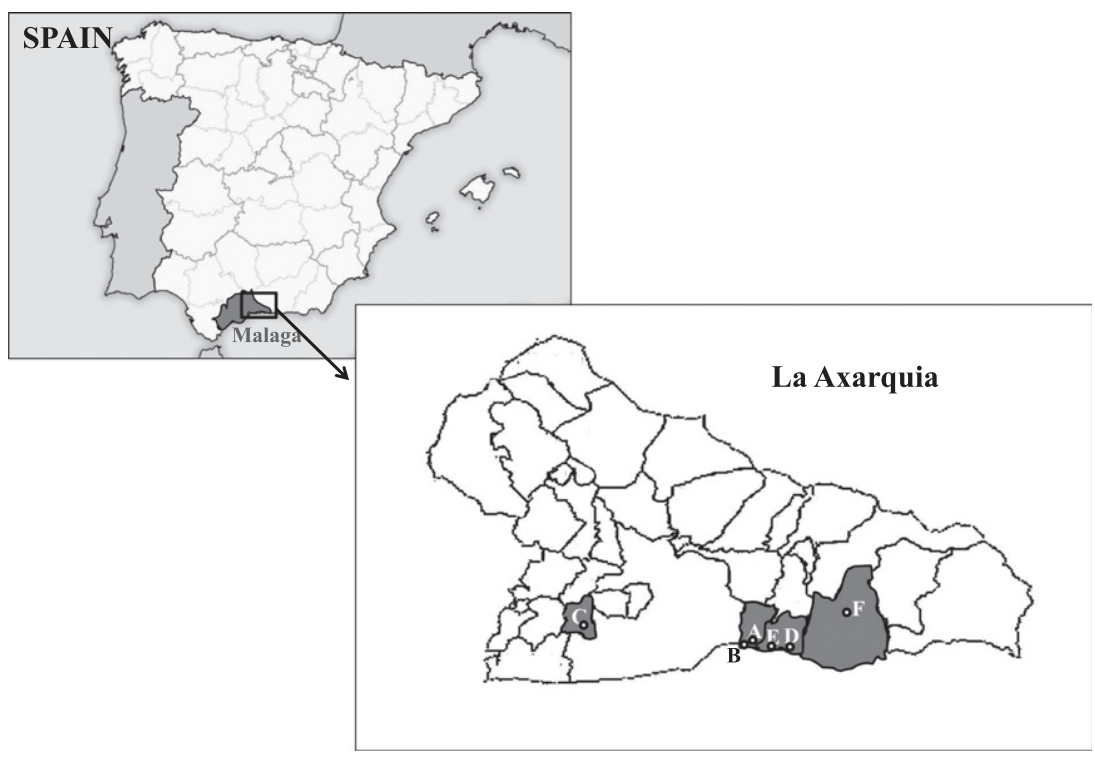

Fig. 1. Location of the mango orchards (A-F) where infected powdery mildew material was collected.
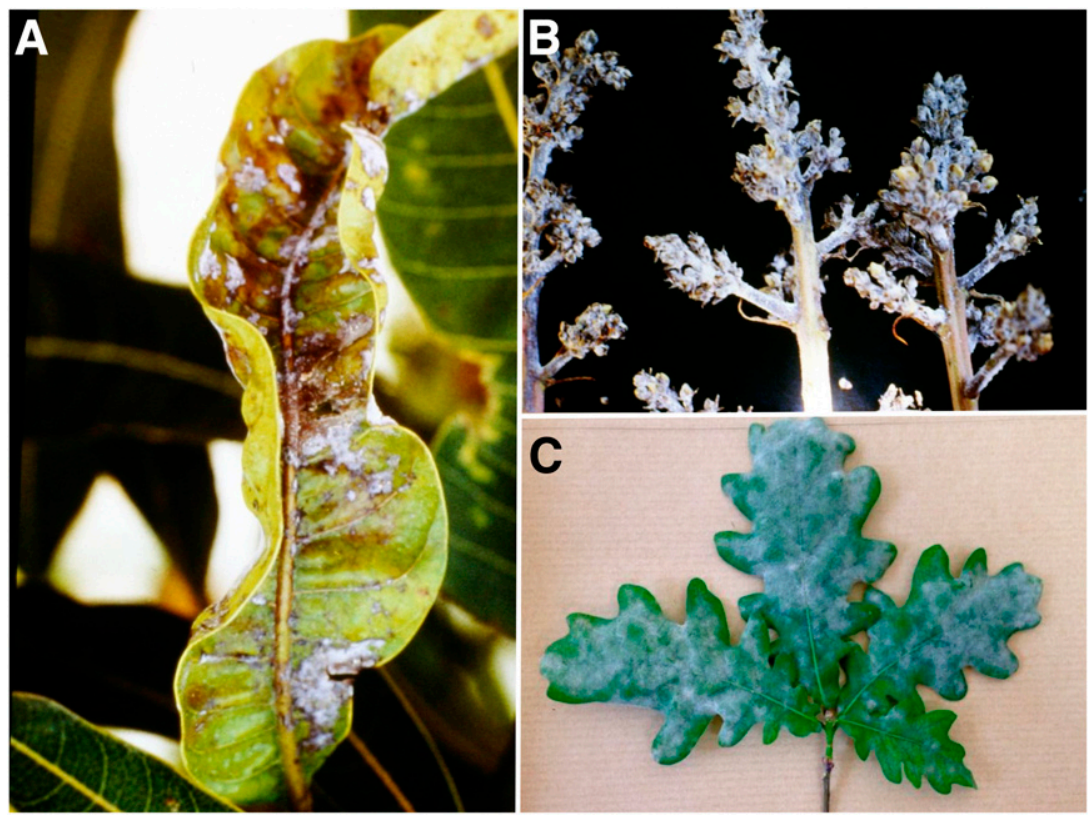

Fig. 2. Typical powdery mildew symptoms on mango leaves (A), inflorescences (B), and oak leaves (C) in Malaga region. 
parameters were estimated from the sequence dataset by PhyML. Node support was assessed through 1,000 nonparametric bootstrap replicates with SPR branch swapping. MP trees were identified by heuristic searches and 100 random additions of sequences (RAS). Node support for MP trees was examined using bootstrapping with 1,000 replicates and the heuristic option with 100 RAS per pseudo replicate. MP and ML consensus phylogenetic trees were then visualized and edited using TreeGraph (Stöver and Müller 2010). Monophyllies not supported by BS $>50 \%$ were considered nonsignificant and collapsed to be treated as polytonies. Topological incongruences between phylogenetic trees were evaluated by inspecting strength of bootstrap support for individual branches as described in Feau et al. (2006).

Pathogenicity assays. To determine if powdery mildew from naturally infected mango was pathogenic on oak seedlings, 4-week-old pedunculate oak seedlings $(Q$. robur, grown from acorns of French origin) were inoculated at the favorable phenological stage, i.e., when leaves were still not fully developed. Inoculation consisted of sweeping a bulk of spores from infected mango leaves and inflorescences onto the oak seedlings using a paintbrush. The infected mango material (cultivars Kent and Irwin) were taken the 5th and 26th of July 2016 from two mango orchards located in Algarrobo-Costa and Lagos (Malaga), respectively. To avoid possible contaminations from the environment, the 10 seedlings (two noninoculated controls and eight inoculated) were maintained in a well isolated greenhouse (double-door entry system, air curtains, air filtration systems to trap small particles such as pollens and spores) at 16-h day and 8-h night light cycle with temperatures ranging between 22 and $30^{\circ} \mathrm{C}$ (as recorded by a thermograph). Presence or absence of powdery mildew symptoms was evaluated 7 days after inoculation. Infected mango material used as inoculum and inoculated oak leaves (in the second trial) were analyzed for the identification of powdery mildew species by sequencing the MS294 gene. The experiments were conducted during the summer 2016 in two different assays carried out the 6th and 27th of July in Spain.

To determine if powdery mildew from oak was pathogenic on mango, seedlings grown from fruits of commercial origin (unknown cultivar and region of origin) in France were inoculated with the paintbrush method described before, at a stage when mango leaves were not fully developed. Powdery mildew inoculum came from two different "isolates" of powdery mildew maintained in the laboratory at INRA, France, one of E. alphitoides ("I47") and the other of E. quercicola ("Eq47"), initially isolated in 2012 from infected oaks in southwest France. The 10 mango seedlings (two noninoculated controls, four inoculated with E. alphitoides, and four with E. quercicola) were grown and incubated in a plant growth chamber at 16-h day and 8-h night light cycle at 26 and $20^{\circ} \mathrm{C}$, respectively. Seedlings were placed in trays covered by a transparent dome during incubation in order to avoid external contaminations. Presence or absence of powdery mildew symptoms was monitored for several weeks after inoculation. Both infected oak leaves used as inoculum and mango leaves after inoculation were analyzed for the identification of powdery mildew species by ITS sequencing. Eight pedunculate oak seedlings $(Q$. robur, same provenance as the one used in Spain) and eight red oak seedlings ( $Q$. borealis) were used as susceptible and non-susceptible references, respectively. They were inoculated in the same conditions and with the same isolates as those used for mango seedlings.

\section{Results}

A morphological examination of the infected mango material confirmed that the anamorphic fungus was of the Pseudoidium type (Fig. 3).

Molecular identification of species. All 149 mango samples analyzed in this work gave a positive amplification with the ITS1Fungi/o-micro-rev primer pair. Among the 149 amplicons, 140 good quality sequences were obtained, with 125 assigned to E. quercicola based on three shared SNPs in the 125 bp long sequence, four sequences were identical to those of $E$. alphitoides, and 11 represented mixtures of the two species (with double peaks clearly visible at the three SNPs on the chromatograms). E. quercicola was the most frequent species in all locations, at all dates and for all organs (Fig. 4). In contrast, frequency of E. alphitoides was generally low (less than $10 \%$ ), although this species was found, alone or in mixture with E. quercicola, in three out of four locations, three out of four cultivars, and from early March to late May. The highest frequency was observed in the first sampling in AlgarroboCosta in early March, especially in leaves, with a frequency of $37.5 \%$ against $8.8 \%$ in inflorescences.

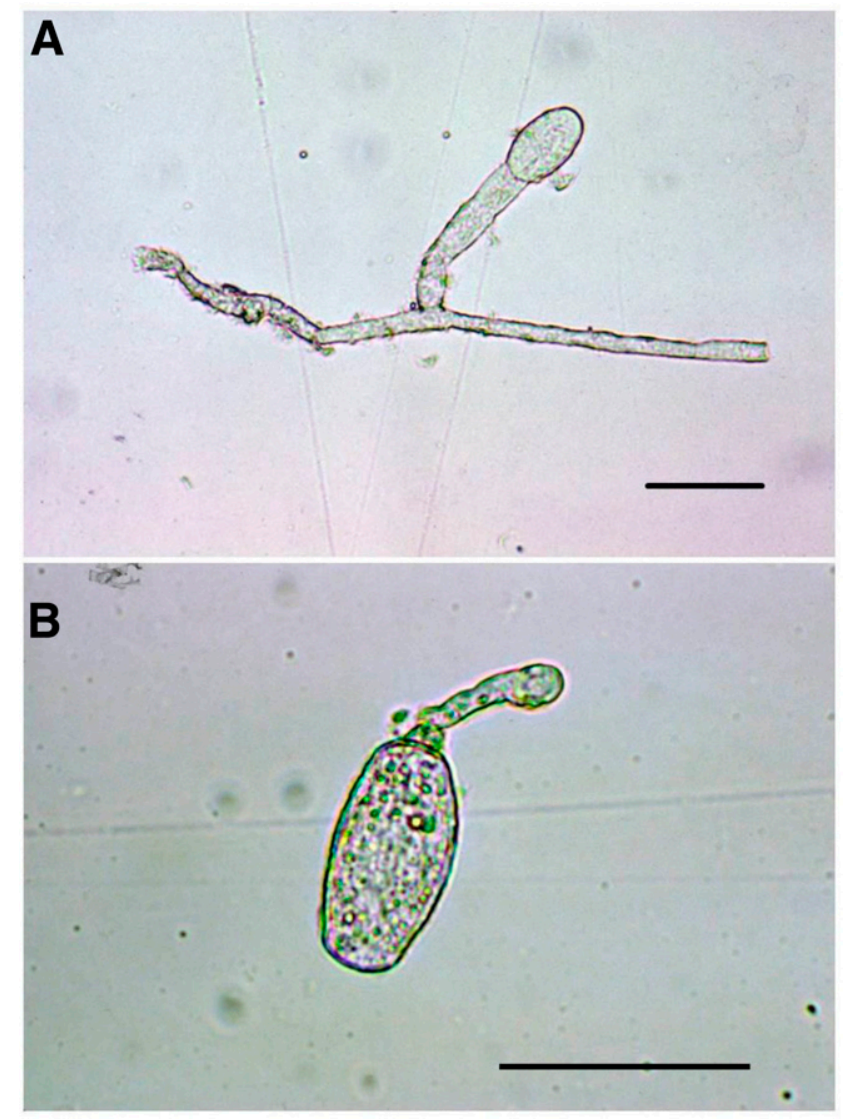

Fig. 3. Conidiophore (A) and conidium (B) under the microscope from samples with typical powdery mildew symptoms collected from commercial mango orchards in southern Spain. The bars represent $50 \mu \mathrm{m}$.

Table 2. Sequences of the oligonucleotidic primers used in this study

\begin{tabular}{|c|c|c|c|c|}
\hline Target gene & Primer designation & Sequence $\left(5^{\prime}-3^{\prime}\right)$ & Amplicon length (bp) & Reference \\
\hline \multirow[t]{2}{*}{ ITS1 } & ITS1-Fungi & CTTGGTCATTTAGAGGAAGTAA & 223 & Gardes and Bruns (1993) \\
\hline & o-micro-rev & GCGCTCCAGCCGAAACC & & Heuser and Zimmer (2002) \\
\hline \multirow[t]{2}{*}{ MS294 } & MS294a & CAATCTTGAGGCATTTTCC & 280 & Feau et al. (2011) \\
\hline & MS294cR & CACGAGGATTCAATCGATG & & \\
\hline \multirow[t]{2}{*}{ MS393 } & MS393e & TTCAACAATTTAATCGGGACCT & 450 & Feau et al. (2011) \\
\hline & MS393f & GGGCGTCGAGAATAGTAAAATG & & \\
\hline \multirow[t]{2}{*}{ MS457 } & MS447d & GTCGCTTTGTATCTAGTCATTC & 357 & Feau et al. (2011) \\
\hline & MS447e & CTGCACCAAAATAAATTTKTC & & \\
\hline \multirow[t]{2}{*}{ MS550 } & MS550f & AATAGACAGGTAAAATCGA & 210 & Feau et al. (2011) \\
\hline & MS550g & CAAACCAACCTTTCTCTCGG & & \\
\hline
\end{tabular}


A subset of 26 selected samples were assigned to E. alphitoides (3 samples), E. quercicola (18), E. alphitoides/E. quercicola mixture (3), or unassigned (2; low quality sequence) based on the first ITS sequencing. These samples were PCR-amplified and sequenced for the four additional genes (MS294, MS393, MS447, and MS550) with an overall success of $93 \%$. The obtained sequences had over $99 \%$ homology with either E. alphitoides or E. quercicola previously described sequences. Sequences of the four genes perfectly matched ITS identifications of $E$. alphitoides and E. quercicola for the 21 pure lesions. The two lesions with unclear ITS sequence were assigned to E. quercicola for the four genes. Finally, E. alphitoides/E. quercicola mixtures were confirmed, either because sequences of the additional genes also showed double peaks at diagnostic SNPs or because either E. alphitoides or E. quercicola sequences were obtained with the four genes.

The high similarity between the sequences obtained for mango samples and that of E. alphitoides or E. quercicola was confirmed by the ML and MP phylogenies. Every gene set but ITS1 resulted in majority rule consensus trees showing strong support for the clustering of mango samples either with E. quercicola or E. alphitoides (bootstrap support [BS] ranging from 62 to 100\%; Fig. 5). However, ITS1 ML and MP trees were poorly resolved with only two statistically supported nodes: E. hypophylla monophyletic supported with BS-values $\geq 85 \%$; and a node including the E. quercicola samples and 13 mango samples with BS-values below 60\% (Fig. 5). This lack of resolution likely resulted from the weak phylogenetic signal already observed in the ITS locus for Erysiphe spp. (Feau et al. 2011). The phylogenies obtained from the concatenated alignments of the five gene sets (ITS1, MS294, MS393, MS447, and MS550; $1,266 \mathrm{bp}, 330$ variable sites) resulted in a single ML tree $(-\mathrm{Ln}=$ 4,008.55) and four equal MP trees of 453 steps; ML and MP trees were $100 \%$ congruent (data not shown). Both MP trees showed a
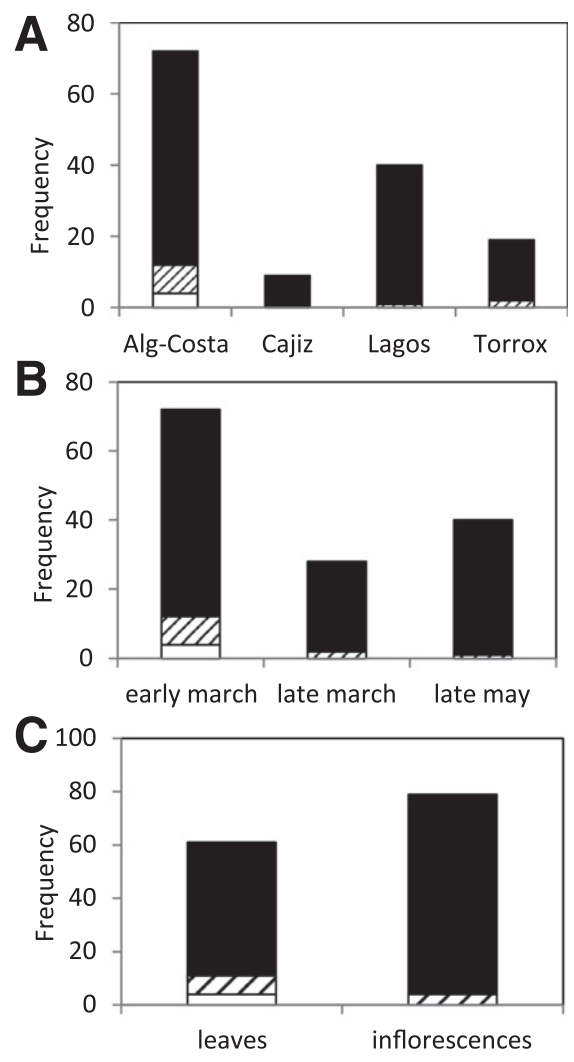

$$
\begin{aligned}
& \text { E. quercicola } \\
& \text { E. quercicola/E. alphitoides } \\
& \text { E. alphitoides }
\end{aligned}
$$

Fig. 4. Erysiphe species detected in infected mango material from Spain according to locations (A), date of sampling (B), and infected organs (C). low level of homoplasy as reflected by the consistency $(82.5 \%)$ and retention $(92.8 \%)$ indexes and the proportion of resolved and statistically supported nodes ( 9 out of 10 nodes resolving species clades; Fig. 6). The monophyletic nodes for E. alphitoides and E. quercicola were both strongly supported with BS of $100 \%$. Thirteen out of the 16 mango samples included in the analysis were gathered within the E. quercicola clade and three with E. alphitoides. Only few intraspecific polymorphisms were observed within the two clades, resulting in weakly to moderately supported (52 to $79 \%$ ) subclades. Within the E. alphitoides clade, a voucher specimen obtained in Japan on Q. crispula (MUMH1954) was differentiated from mango samples and other E. alphitoides collected on oaks in Europe (Fig. 6). Within the E. quercicola clade, most of the intraspecific polymorphisms (3 out of 4) were found in MS447, resulting in two oak samples collected in Europe (GEM 0914 and GEM 09 16) differentiated from other E. quercicola and related mango samples (BS of $86 \%$ in ML and $75 \%$ in MP) and two mango samples resolved in one node that received a BS of $59 \%$ in ML and $63 \%$ in MP (Fig. 6). In addition, the oak samples collected in Europe differed from all the other samples (including those collected on mango) by one ' $\mathrm{T}$ ' to ' $\mathrm{C}$ ' substitution at position 301 in the MS447 gene; however, even if this SNP was unique and fixed in the seven E. quercicola samples from oak (meaning that the alternative base ' $\mathrm{T}$ ' is shared between all other samples and species, including those from mango), it did not result in a well-supported subclade for the oak isolates as this short node was only supported in the ML tree with a BS of $57 \%$.

The 19 samples taken from different leaves in a single oak tree (Q. robur) that was infected by powdery mildew were all of the E. alphitoides type based on polymorphisms in ITS1 and the four other gene sequences. Sequences obtained for three representative samples (MalQr1 to MalQr3) all clustered with sequences of other E. alphitoides samples from mango and oaks (Figs. 5 and 6).

Pathogenicity tests. Oak seedlings inoculated with mango powdery mildew showed typical symptoms on both sides of leaves 1 week after inoculation. All eight seedlings were infected with between 30 and $50 \%$ of the total leaf area covered by fungal mycelium and spores. Infected mango leaves and inflorescences that had been used for oak inoculations only yielded E. quercicola (from 10 analyzed samples), and E. quercicola was retrieved from inoculated oak seedlings (from 20 analyzed samples), according to MS294 sequencing. No symptoms developed on control (noninoculated) oak seedlings.

Mango seedlings inoculated with spore material collected from infected oak leaves (either E. quercicola or E. alphitoides) showed first symptoms between 7 and 14 days. Little infection on a few leaves, especially along leaf veins, was observed after the inoculation of E. alphitoides on two seedlings. In contrast, extensive lesions covering the whole leaf surface on the youngest leaves and extending on shoots (and the subsequent growth unit in one seedling) were observed after E. quercicola inoculation on two out of the four inoculated seedlings. Molecular identifications using the ITS1 sequence confirmed E. alphitoides and E. quercicola presence in corresponding inoculated seedlings. No symptoms developed in noninoculated mango seedlings.

No symptoms were observed on red oak seedlings, the nonsusceptible reference species, inoculated with either Erysiphe sp. from $Q$. robur. Conversely, all inoculated pedunculate oak seedlings, the susceptible reference species, were highly infected, both with E. alphitoides and E. quercicola.

\section{Discussion}

To our knowledge, this is the first report of E. quercicola and E. alphitoides causing powdery mildew on mango trees in mainland Spain, and thus mainland Europe, based on unequivocal phylogenetic and biological evidence. Previous reports of "Oidium mangiferae" for Europe summarized in distribution maps (CABI/EPPO 2010; Nasir et al. 2014) were in Crete and the Canary islands, although reports of the disease in mainland Spain were already available in the "gray literature" (Torés 1991).

Identification of E. alphitoides and E. quercicola performed in this study was based on the congruent phylogenetic signal of five genes 
and summarized through the reconstruction of a multigene phylogeny. Sequences from mango isolates were $\sim 99$ to $100 \%$ identical to those from oak isolates; no difference was observed with $E$. alphitoides sequences and only one fixed substitution with $E$. quercicola out of the five genes alignment of 1,266 bp. As this SNP seems to be private to the E. quercicola samples from European oaks, it likely resulted from a substitution that happened after the spread of the species E. quercicola on this host in Europe. Our results showed that the main species associated with mango powdery mildew in Europe is E. quercicola, as was also reported in other regions (Limkaisang et al. 2006). However, E. alphitoides was found in several orchards at various dates, and in three different cultivars, ruling out the likelihood of a contamination and demonstrating the ability of this species to infect mango, as also found by Limkaisang et al. (2006). The lower frequency of $E$. alphitoides in inflorescences compared with leaves, observed in the same orchard, suggests a lower virulence of this species

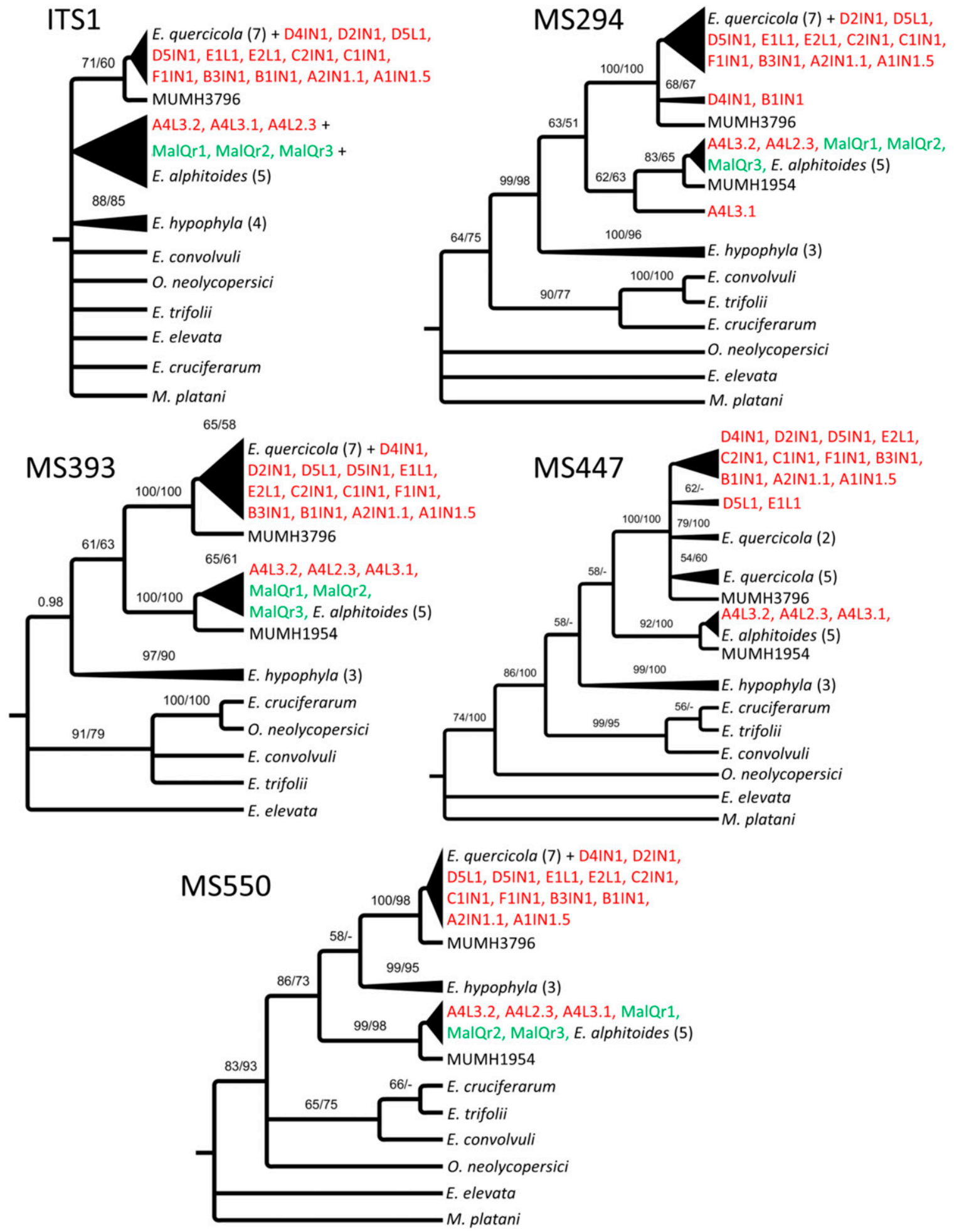

Fig. 5. Maximum likelihood trees obtained with ITS1 and four nuclear coding gene (MS294, MS447, MS393, and MS550) alignments for oak powdery mildews and related Erysiphe/ Oidium species (cf Feau et al. 2011; Takamatsu et al. 2007), together with powdery mildew samples from mango trees (this study). Bootstrap support values (of 1,000 pseudoreplicates) above 50\% are presented on nodes as follows: ML bootstrap value/MP bootstrap value. Mango samples are in red (ID = field_id-tree\#-organ (Leaf/ INflorescence)-organ\#.replicate); oak samples (Quercus robur) collected in Algarrobo-Costa (orchard A) beside infected Mango trees (ID = MalQr) are in green. 
toward floral organs, which would lead to lower agronomic impact and might explain less frequent reports.

Our inoculation experiments further supported the pathogenicity of E. alphitoides and E. quercicola isolates from mango on oaks and reciprocally from oak isolates on mango. However, our experiment suggested that E. quercicola is more virulent than E. alphitoides on mango. Since oak inoculations were performed in a region of Spain with very low occurrence of oaks, and mango inoculations were performed in France where mango does not occur, contaminations by a local inoculum were very unlikely, as supported by the absence of any infection on noninoculated seedlings. Although artificial inoculations under controlled conditions may favor infection (high inoculum pressure, environmental conditions) and need to be interpreted with caution as they probably overestimate plant susceptibility (Glawe 2008), the intensity of symptoms that were observed both in oak and mango with "heterologous" powdery mildew suggested true susceptibility. Moreover, the absence of symptoms in a host known to have little susceptibility to European oak powdery mildew, i.e., red oak seedlings (Mougou et al. 2008), is a further indication that our results are consistent with true susceptibility of mango seedlings to the tested isolates coming from oaks and reciprocally.

Our findings might give further support to the hypothesis that oak powdery mildew was introduced to Europe by early Portuguese explorers on tropical plants, including mango trees (Boesewinkel 1980; Mougou et al. 2008; Raymond 1927). It should be noted that

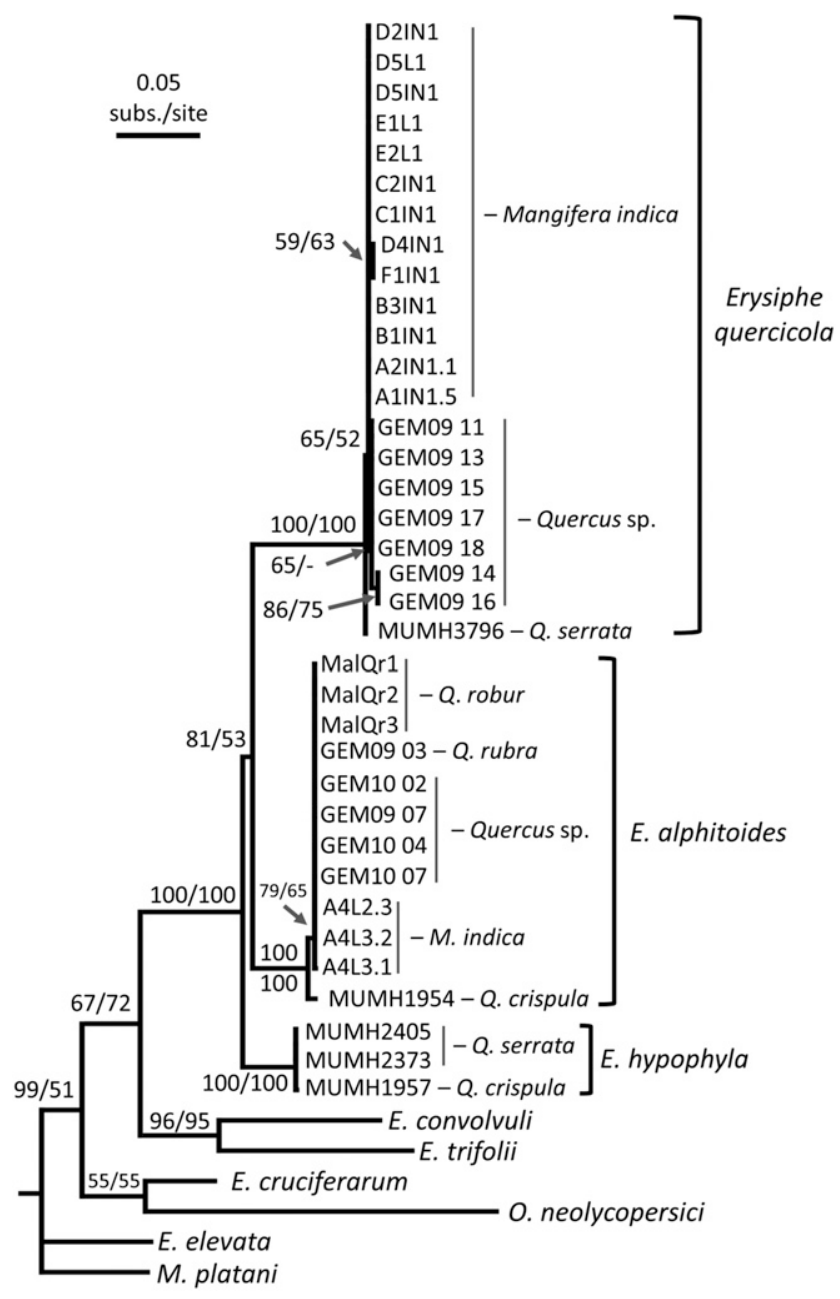

Fig. 6. Phylogenetic relationships among oak powdery mildews (from Feau et al. 2011; Takamatsu et al. 2007) and powdery mildew samples from mango trees (this study). Maximum likelihood tree constructed from the concatenation of ITS1 and four nuclear coding gene (MS294, MS447, MS393, and MS550) alignments assuming a GTR+G sequence evolution model. Bootstrap support values (of 1,000 pseudoreplicates) above $50 \%$ are presented on nodes as follows: ML bootstrap value/MP bootstrap value. Mango samples ID as in Fig. 5. although only E. alphitoides was detected on $Q$. robur in this study, we found both E. alphitoides and E. quercicola on oaks in other samplings in Spain (unpublished results). However, phylogenetic evidence suggested that primary hosts of E. alphitoides and E. quercicola were Asian oaks (Takamatsu et al. 2007). Deciphering the complete history of this invasion might therefore be not straightforward and will require more studies, using for example phylogeographic approaches.

Whatever the original host of both Erysiphe spp., our results highlight the peculiarity of these two powdery mildew species that were able to perform host range expansions on plant species distantly related to their original host, and which show wide host ranges, unlike most powdery mildew species. The probability that two plant species share a common pathogen has been shown to decrease rapidly with phylogenetic distance as a general trend (Gilbert and Webb 2007). However, host jumps on distantly related plant species have been reported in other biotrophic plant pathogens, such as smuts (Sharma et al. 2014), and some other powdery mildew species (Beenken 2017; Takamatsu et al. 2015; Vági et al. 2007). Increasing evidence suggests the key role of the fungal effector repertoire to explain host range (Schulze-Lefert and Panstruga 2011). Since both E. quercicola and $E$. alphitoides show the same characteristics while several other closely related Erysiphe spp. in the same clade have been strictly associated with oaks so far (Takamatsu et al. 2007, 2015), the most parsimonious hypothesis is that the ability to infect a wide host range was acquired by E. alphitoides and E. quercicola from a close common ancestor. Comparative genome analyses among and within closely related species might help to point out the effectors involved in host range width in this group (Sharma et al. 2014). Our study, adding to the accumulated evidence that oak and mango powdery mildew are caused by the same species, emphasizes the need for a reappraisal of literature, which up to now has considered the two diseases separately (e.g., Marçais and Desprez-Loustau 2014; Nasir et al. 2014).

From a more general point of view, our results are further evidence of the ability of plant pathogens, including putative specialists, to perform host jumps (Slippers et al. 2005) and thus of the risk of emerging diseases from the introduction of pathogens on exotic plants. The gene sets obtained with the PHYLORPH method (Feau et al. 2011), with their high resolution ability for species complexes, could be useful in many cases to ascertain identification of pathogens observed on unusual host plants, and thus support or reject a distant host jump (Beenken 2017).

\section{Acknowledgments}

The authors are very grateful to Gilles Saint-Jean, Olivier Fabreguettes and Xavier Capdevielle for technical help. This work was supported by a grant from the French National Research Agency (ANR) as part of the "Blanc 2013" program (ANR-13-BSV7-0011, FunFit project) and grants from CICE-Junta de Andalucia, Proyecto de Excelencia P12-AGR-1473 and from Plan Nacional I+D+I Spanish Government (MINECO) AGL2013-41939-R, co-financed by FEDER funds (EU).

\section{Literature Cited}

Anonymous. 2015. Ministerio de Agricultura, Pesca y Alimentación, Gobierno de España. Estadísticas agrarias, http://www.mapama.gob.es/es/estadistica/temas/ estadisticas-agrarias/agricultura/esyrce/

Beenken, L. 2017. First records of the powdery mildews Erysiphe platani and E. alphitoides on Ailanthus altissima reveal host jumps independent of host phylogeny. Mycol. Prog. 16:135-143.

Bereczky, Z., Pintye, A., Csontos, P., Braun, U., and Kiss, L. 2015. Does the parasite follow its host? Occurrence of morphologically barely distinguishable powdery mildew anamorphs on Oenothera spp. in different parts of the world. Mycoscience 56:267-272.

Boesewinkel, H. J. 1980. The morphology of the imperfect state of powdery mildew (Erysiphaceae). Bot. Rev. 46:167-224.

Braun, U. 2012. The impacts of the discontinuation of dual nomenclature of pleomorphic fungi: the trivial facts, problems, and strategies. IMA Fungus 3:81-86.

Braun, U., and Cook, R. T. A. 2012. Taxonomic manual of the Erysiphales (powdery mildews). CBS Biodivers. Ser. No. 11. CBS-KNAW Fungal Biodivers. Centre, Utrecht, The Netherlands.

Briton-Jones, H. R. 1925. Mycological work in Egypt during the period 19201922. Egypt Min. Agr. Tech. Sci. Serv. Bull. 49.

CABI/EPPO. 2010. Oidium mangiferae. Distribution map 1081 (edition 1) Distribution Maps of Plant Diseases, April 2010. CABI, Wallingford, U.K.

Cook, R. T. A., Inman, A. J., and Billings, C. 1997. Identification and classification of powdery mildew anamorphs using light and scanning electron microscopy and host range data. Mycol. Res. 101:975-1002. 
Darriba, D., Taboada, G. L., Doallo, R., and Posada, D. 2012. jModelTest 2: more models, new heuristics and parallel computing. Nat. Methods 9:772.

Denton, G. J., Denton, J. O., and Cook, R. T. A. 2016. First record of Erysiphe alphitoides on Wisteria brachybotrys and $W$. frutescens, and first record of its chasmothecia on Wisteria. New Dis. Rep. 33:5.

Feau, N., Decourcelle, T., Husson, C., Desprez-Loustau, M. L., and Dutech, C. 2011. Finding single copy genes out of sequenced genomes for multilocus phylogenetics in non-model fungi. PLoS One 6:e18803.

Feau, N., Hamelin, R. C., and Bernier, L. 2006. Attributes and congruence of three molecular data sets: Inferring phylogenies among Septoria-related species from woody perennial plants. Mol. Phylogenet. Evol. 40:808-829.

Gams, W. 2016. Recent Changes in Fungal Nomenclature and Their Impact on Naming of Microfungi. Pages 7-23 in: Biology of Microfungi. D.-W. Li, ed. Springer International Publishing, Cham, Switzerland.

Gardes, M., and Bruns, T. D. 1993. ITS primers with enhanced specificity for basidiomycetes- Application to the identification of mycorrhizae and rusts. Mol. Ecol. 2:113-118.

Gilbert, G. S., and Webb, C. O. 2007. Phylogenetic signal in plant pathogen-host range. Proc. Natl. Acad. Sci. 104:4979-4983.

Glawe, D. A. 2008. The powdery mildews: a review of the world's most familiar (yet poorly known) plant pathogens. Phytopathology 46:27-51.

Guindon, S., and Gascuel, O. 2003. A simple, fast, and accurate algorithm to estimate large phylogenies by maximum likelihood. Syst. Biol. 52:696-704.

Hall, T. A. 1999. BioEdit: a user-friendly biological sequence alignment editor and analysis program for Windows 95/98/NT. Nucleic Acids Symp. Ser. 41:95-98.

Henricot, B., and Cook, R. T. A. 2007. New report of powdery mildew on Wisteria in the UK. New Dis. Rep. 15:17.

Heuser, T., and Zimmer, W. 2002. Quantitative analysis of phytopathogenic ascomycota on leaves of pedunculate oaks (Quercus robur L.) by real-time PCR. FEMS Microbiol. Lett. 209:295-299.

Kirschner, R., and Liu, W. A. 2014. Two new hosts of anamorphic Erysiphe quercicola: Cinnamomum camphora and Murraya paniculata. Mycoscience 55:190-195.

Kiss, L., Jankovics, T., Kovacs, G. M., and Daughtrey, M. L. 2008. Oidium longipes, a new powdery mildew fungus on petunia in the USA: A potential threat to ornamental and vegetable solanaceous crops. Plant Dis. 92:818-825.

Kovacs, G. M., Jankovics, T., and Kiss, L. 2011. Variation in the nrDNA ITS sequences of some powdery mildew species: do routine molecular identification procedures hide valuable information? Eur. J. Plant Pathol. 131:135-141.

Limkaisang, S., Cunnington, J. H., Wui, L. K., Salleh, B., Sato, Y., Divarangkoon, R., Fangfuk, W., To-anun, C., and Takamatsu, S. 2006. Molecular phylogenetic analyses reveal a close relationship between powdery mildew fungi on some tropical trees and Erysiphe alphitoides, an oak powdery mildew. Mycoscience 47:327-335.

Lipka, U., Fuchs, R., and Lipka, V. 2008. Arabidopsis non-host resistance to powdery mildews. Curr. Opin. Plant Biol. 11:404-411.

Marçais, B., and Desprez-Loustau, M. L. 2014. European oak powdery mildew: impact on trees, effects of environmental factors, and potential effects of climate change. Ann. For. Sci. 71:633-642.

Marçais, B., Piou, D., Dezette, D., and Desprez-Loustau, M. L. 2017. Can oak powdery mildew severity be explained by indirect effects of climate on the composition of the Erysiphe pathogenic complex? Phytopathology (in press). doi:10.1094/PHYTO-07-16-0268-R

Meeboon, J., and Takamatsu, S. 2015. Notes on powdery mildews (Erysiphales) in Japan: III. Golovinomyces and Podosphaera. Mycoscience 56:243-251.

Mougou, A., Dutech, C., and Desprez-Loustau, M. L. 2008. New insights into the identity and origin of the causal agent of oak powdery mildew in Europe. For. Pathol. 38:275-287.

Mougou-Hamdane, A., Giresse, X., Dutech, C., and Desprez-Loustau, M. L. 2010 Spatial distribution of lineages of oak powdery mildew fungi in France, using quick molecular detection methods. Ann. For. Sci. 67:212.

Nasir, M., Mughal, S. M., Mukhtar, T., and Awan, M. Z. 2014. Powdery mildew of mango: A review of ecology, biology, epidemiology and management. Crop Prot. 64:19-26.

Nelson, S. C. 2008. Mango powdery mildew. Plant Disease, August 2008, PD-46. College of Tropical Agriculture and Human Resources, University of Hawaii at Manoa. Online: https://www.ctahr.hawaii.edu/oc/freepubs/pdf/PD-46.pdf

Raymond, J. 1927. Le blanc du chêne. Ann. Epiphyt. 13:94-129.

Schulze-Lefert, P., and Panstruga, R. 2011. A molecular evolutionary concep connecting non host resistance, pathogen host range, and pathogen speciation. Trends Plant Sci. 16:117-125.

Sharma, R., Mishra, B., Runge, F., and Thines, M. 2014. Gene loss rather than gene gain is associated with a host jump from monocots to dicots in the smut fungus Melanopsichium pennsylvanicum. Genome Biol. Evol. 6:2034-2049.

Singh, R. S. 2000. Powdery mildew of mango. Pages 157-159 in: Diseases of Fruit Crops. Oxford and IBH Publishing Co, New Delhi.

Slippers, B., Stenlid, J., and Wingfield, M. J. 2005. Emerging pathogens: funga host jumps following anthropogenic introduction. Trends Ecol. Evol. 20: 420-421.

Stöver, B. C., and Müller, K. F. 2010. TreeGraph 2: Combining and visualizing evidence from different phylogenetic analyses. BMC Bioinformatics 11:7.

Swofford, D. L. 2003. PAUP 4.0 user's manual: phylogenetic analysis using parsimony. Sinauer Associates Inc., Sunderland, MA.

Takamatsu, S., Arakawa, H. I., Shiroya, Y., Kiss, L., and Heluta, V. 2015. First comprehensive phylogenetic analysis of the genus Erysiphe (Erysiphales, Erysiphaceae) I. The Microsphaera lineage. Mycologia 107:475-489.

Takamatsu, S., Braun, U., Limkaisang, S., Kom-Un, S., Sato, Y., and Cunnington, J. H. 2007. Phylogeny and taxonomy of the oak powdery mildew Erysiphe alphitoides sensu lato. Mycol. Res. 111:809-826.

Takamatsu, S., Inagaki, M., Niinomi, S., Khodaparast, S. A., Shin, H. D., Grigaliunaite, B., and Havrylenko, M. 2008. Comprehensive molecular phylogenetic analysis and evolution of the genus Phyllactinia (Ascomycota: Erysiphales) and its allied genera. Mycol. Res. 112:299-315.

Torés, J. A. 1991. El oídio del mango. Frutos Tropicales 2:27-30.

Torrend, C. 1909. L'Oidium du Chene en Portugal et a l'ile de Madere. Brotéria: Rev. Sci. Natur. Collegio S. Fiel. Ser. Bot. VIII:103-113.

Troch, V., Audenaert, K., Wyand, R. A., Haesaert, G., Höfte, M., and Brown, J. K. 2014. Formae speciales of cereal powdery mildew: close or distant relatives? Mol. Plant Pathol. 15:304-314.

Vági, P., Kovacs, G. M., and Kiss, L. 2007. Host range expansion in a powdery mildew fungus (Golovinomyces sp.) infecting Arabidopsis thaliana: Torenia fournieri as a new host. Eur. J. Plant Pathol. 117:89-93. 